\title{
Evaluation Index System and Evaluation Method of China's Regional Potential for Electrical Energy Substitution
}

\author{
Yanmei Li and Zeng Chen \\ School of Economics and Management, North China Electric Power University, 071003 Baoding, Hebei, China \\ Correspondence should be addressed to Zeng Chen; 811359665@qq.com
}

Received 30 May 2018; Accepted 19 June 2018; Published 9 July 2018

Academic Editor: Vincenzo Bianco

Copyright ( 2018 Yanmei Li and Zeng Chen. This is an open access article distributed under the Creative Commons Attribution License, which permits unrestricted use, distribution, and reproduction in any medium, provided the original work is properly cited.

\begin{abstract}
Electrical energy substitution is used as a national strategy to promote the energy consumption revolution, increase the proportion of electric energy in terminal energy consumption, increase the proportion of coal used for power generation in total coal consumption, increase the share of renewable energy in electricity consumption, and reduce air pollutant emissions; its importance in the national energy strategy is beyond doubt. Evaluating the potential of electrical energy substitution in various regions of China is an indispensable step in effectively carrying out electrical energy substitution. Only by clearly identifying the potential and characteristics of electrical energy substitution in each region can an effective electrical energy substitution strategy be formulated. This paper constructs a regional electrical energy substitution potential evaluation index system, based on comprehensive consideration of the influencing factors and regional differences in the potential of electrical energy substitution. The weight of each indicator is determined by a combination of cloud model and entropy method. The improved Technique for Order Preference by Similarity to an Ideal Solution (TOPSIS) evaluation model by connection degree is used to evaluate the potential of electrical energy substitution in each region. Finally, this index system and evaluation method are used to evaluate the potential of electrical energy substitution in twenty-five regions in the State Grid jurisdiction, and the evaluation results are analyzed; the effectiveness of evaluation index system and evaluation method are verified. The practical significance of this paper lies in providing important theoretical support for State Grid to implement electrical energy substitution according to local conditions.
\end{abstract}

\section{Introduction}

Energy is the foundation for human survival and modernization. At present, the international energy landscape is undergoing profound changes. The path of global energy transformation is still being explored. China is also actively promoting the energy revolution to solve related issues including energy security and environmental pressure. In this context, electrical energy substitution faces a rare historical opportunity. In 2015, electricity consumption accounts for $25.8 \%$ of China's total energy consumption. It is estimated that, by 2020 , the proportion of electricity consumption will reach $27 \%$. Electrical energy substitution work has important energy-saving and environmental-friendly effects, which is in line with the energy consumption revolution. In addition, at present, the proportion of electric energy consumption in terminal energy consumption is relatively low, and the effectiveness of energy-saving and environmental protection in the end-use energy segment has a multiplier effect. Therefore, there is a great potential for electrical energy substitution and its urgent needs to be promoted in an orderly manner. The Chinese government has also actively promoted the implementation of electrical energy substitution strategy through various forms, such as policy documents.

Electrical energy substitution has been extensively studied internationally, especially in developed countries. On the macro level, electrical energy substitution can reduce pollution and greenhouse gas emissions. Scholars have demonstrated that electrical energy substitution could reduce greenhouse gas emissions from various aspects, such as power generation, transportation, industrial, residential consumption, energy for commercial buildings, cement industry, and steel industry $[1,2]$. In China, electrical energy substitution as a part of the energy development strategy is of great significance in promoting the energy consumption revolution. At present in China, the research of electrical energy 
substitution mainly focuses on the four topics: residential heating, manufacturing, transportation, power supply, and consumption. Its purpose is also to reduce greenhouse gas emissions and improve energy efficiency. On the micro level, the electrical energy substitution of daily-use vehicles, agricultural machinery, and kitchen boilers has also been extensively studied $[3,4]$. For example, in the United States, the issue of electric vehicles is a hot topic $[5,6]$. In China, the electrical energy substitution in the field of residential heating is a research hot spot; a large number of scholars have studied the feasibility and economics of electrifying winter heating in the Beijing-Tianjin-Hebei area [7]. At the same time, electrical energy substitution is also a means of reducing poverty [8]. Electricity supply demand balance, peak electricity, and power grids [9], a region's energy micro grid, rural sustainable electrification, and electrification economy [10-13] are also hot topics to study. In promoting the implementation of electrical energy substitution, ZhangJing gave some suggestions based on the research, for example, full integration of resources, full grasp of opportunities, full data support, rapid business management, technology promotion, and government subsidies [14].

According to the combining of previous literatures, it can be found that there is no systematic and in-depth study of the current electrical energy substitution work in China; especially the research on regional electrical energy substitution potential evaluation is even less. Therefore, aiming at the blank of this research field, this paper evaluates the potential of regional electrical energy substitution in China.

This paper constructs a regional electrical energy substitution potential evaluation index system that includes five first-level indicators and sixteen second-level indicators based on comprehensive consideration of the influencing factors and regional differences in the potential of electrical energy substitution. In order to minimize the impact of human subjective, this paper adopts a cloud model that is widely used in many fields to quantify the languages for humans evaluating the importance of indicators subjectively. At the same time, considering the objectivity of the indicator itself, this paper uses the combination of cloud model and entropy method to determine the weight of each indicator. Because the Technique for Order Preference by Similarity to an Ideal Solution (TOPSIS) has a certain deficiencies, in order to overcome the deficiencies, the connection degree is used to improve the TOPSIS method, and then the improved TOPSIS method is used to evaluate the potential of electrical energy substitution in each region and the validity of the evaluation method is verified through case.

The main contributions of this paper are as follows:

(1) This paper evaluates the potential of regional electrical energy substitution from the perspective of the electrical energy substitution potential. Based on the characteristics of regional electrical energy substitution potential, a set of indicator system suitable for the evaluation of regional electrical energy substitution potential is constructed, including five first-level indicators and sixteen second-level indicators.

(2) In order to overcome the deficiencies of the subjective and objective weighting methods, this paper uses the combination weighting method, i.e., the combination of the cloud model and the entropy weighting method to determine the weight of each indicator. The TOPSIS method improved by the connection degree is used to evaluate the potential of electrical energy substitution in each region, and the validity of the evaluation method is verified with case.

(3) According to the evaluation results of the potential of electrical energy substitution in each region, twenty-five regions are divided into four categories and the factors that affect the potential of electrical energy substitution in various categories are analyzed, and corresponding electrical energy substitution implementation strategies are put forward. It provides important theoretical support for grid companies to implement electrical energy substitution, production management, and decision-making reference according to local conditions.

\section{Evaluation Index System for China's Regional Electrical Energy Substitution Potential}

2.1. Index System Construction. The establishment of a regional evaluation index system for the potential of electrical energy substitution plays an important role in the reasonable and effective evaluation of the potential of electrical energy substitution in each region. In literature [15] when evaluating the comprehensive benefits of electrical energy substitution projects, a comprehensive benefit evaluation index system was constructed based on national development policies and experiences from the external environment, company profitability, and social contribution. Literature $[13,16,17]$ evaluates the technical feasibility, economic benefits, and environmental benefits of electrical energy substitution. The indicators for evaluation are mainly the existing electrical energy substitution technologies, cost, and air pollution emissions reductions. According to the existing literatures on the study of electrical energy substitution and national policies. It can be concluded that if electrical energy substitution is to be developed, it must be technically feasible, economical, and environmentally friendly. It can be seen from the existing researches that the current researches on the evaluation of electrical energy substitution mainly focus on (1) the comprehensive benefits of electrical energy substitution, mainly including environmental benefits, social benefits, and economic benefits; (2) the competitiveness of electric energy in terminal energy use; (3) electrical energy substitution for fuel vehicles. From the comprehensive evaluation index system, the index systems established by scholars are mostly multilevel index systems covering energy, economy, and environment. As for the evaluation of China's regional electrical energy substitution potential, researches are rarely involved. At present, there is not a complete set of electrical energy substitution potential evaluation index system that can be used as a reference. Therefore, based on the existing evaluation index system of electrical energy substitution combined with the factors that affect the potential of electrical energy substitution and the characteristics of electrical energy substitution, we establish a set of indicators system that can be used to evaluate the regional electrical energy substitution potential. As a relatively new thing, electrical 
TABLE 1: The evaluation index system of China's regional electrical energy substitution potential.

\begin{tabular}{|c|c|c|c|c|}
\hline Objective & Criterial & Index & Index attribute & Index type \\
\hline \multirow{16}{*}{$\begin{array}{l}\text { Evaluation of China's } \\
\text { Regional Potential for } \\
\text { Electrical Energy } \\
\text { Substitution }\end{array}$} & \multirow{3}{*}{$\begin{array}{l}\text { Social and economic } \\
\text { development level }\end{array}$} & GDP I1 & quantitative & maximum \\
\hline & & Population I2 & quantitative & maximum \\
\hline & & Coal consumption I3 & quantitative & maximum \\
\hline & \multirow{3}{*}{$\begin{array}{l}\text { Energy consumption } \\
\text { structure }\end{array}$} & Crude oil consumption I4 & quantitative & maximum \\
\hline & & Natural gas consumption I5 & quantitative & minimal \\
\hline & & Electricity consumption I6 & quantitative & maximum \\
\hline & \multirow{3}{*}{$\begin{array}{l}\text { Environmental protection } \\
\text { constraints }\end{array}$} & Annual scattered coal consumption I7 & quantitative & maximum \\
\hline & & Annual air PM2.5 average concentration I8 & quantitative & maximum \\
\hline & & Number of motor vehicles I9 & quantitative & maximum \\
\hline & \multirow{5}{*}{ Economical efficiency } & Industrial gas price I10 & quantitative & maximum \\
\hline & & Resident gas price I11 & quantitative & maximum \\
\hline & & Residential electricity price I12 & quantitative & minimal \\
\hline & & Industrial electricity price I13 & quantitative & minimal \\
\hline & & General industrial and commercial electricity price I14 & quantitative & minimal \\
\hline & \multirow{2}{*}{ Supporting support } & Support policies I15 & qualitative & maximum \\
\hline & & Electricity surplus and shortage I16 & quantitative & maximum \\
\hline
\end{tabular}

energy substitution needs the driving force of development, which mainly includes the adjustment of the national energy consumption structure and corresponding supporting support policies. As socioeconomic development is also the main reason for promoting changes in energy structure. Therefore, this paper will use the above factors that affect the potential of electrical energy substitution as the basis for selecting indicators, at the same time, considering the need to assess the potential for electrical energy substitution in multiple regions. As electrical energy substitution technologies within the country are available in all regions, in order to distinguish the differences among regions, this paper does not select technical feasibility as an evaluation index. Since natural gas is also widely promoted by the state as a clean energy source, the economics of electricity are mainly compared with natural gas. Based on the above analysis, this paper divides the evaluation index of China's regional electrical energy substitution potential into five aspects: social and economic development level, energy consumption structure, environmental protection constraints, economical efficiency, and supporting support. The specific indicators are shown in Table 1 .

\subsection{Index System Analysis}

2.2.1. Social and Economic Development Level. The level of social and economic development is expressed in terms of GDP and population.

(1) GDP. In general, the higher the GDP, the more developed the region, the higher the degree of emphasis on energy, the higher the level of electrification, and the greater the potential for electrical energy substitution.

(2) Population. The population is directly proportional to the amount of energy consumed. The more people there are, the greater the potential for electrical energy substitution is.

2.2.2. Energy Consumption Structure. The energy consumption structure mainly includes coal consumption, crude oil consumption, natural gas consumption, and electricity consumption.

(1) Coal, Crude Oil, and Electricity Consumption. The potential for electrical energy substitution lays mainly that electricity instead of coal and oil; therefore, the greater the coal and crude oil consumption in a region, the greater the potential for electrical energy substitution in the region.

(2) Natural Gas Consumption. Natural gas is considered a relatively clean energy source that the country vigorously promotes and uses, and it is a competitor of electric energy. The greater the consumption of natural gas in a region, the greater the resistance to competition for electrical energy replacement in the region and the smaller the potential for electrical energy replacement.

2.2.3. Environmental Protection Constraints. Under the criteria of environmental protection constraints, there are mainly three secondary indicators, namely, annual amount of scattered coal burned (including rural life, accommodation and catering, urban life, and agricultural life), annual average air PM2.5 concentration, and motor vehicle ownership.

(1) The Annual Scattered Coal Consumption. Scattered coal (abbreviated as bulk coal) is the key and difficult point in controlling air pollution prevention and coal treatment. Relative to concentrated coal combustion, scattered coal is widely used, and it is difficult to supervise. Civilians often use low-quality coal with high ash content and high sulfur content. After combustion, it often lacks desulfurization, 
denitrification, and dust removal. The unit emission intensity of bulk coal is much higher than that of concentrated coal, and the emission intensity of scattered coal is about eight times of that of electric coal. Therefore, the annual scattered coal consumption in a region is a driving factor for environmental protection requirements. The larger the amount of scattered coal burned, the greater the potential for electrical energy substitution.

(2) Annual Air PM2.5 Average Concentration. The more severe the forms of environmental protection in a region, the greater the opportunities for the development of electrical energy substitution; the concentration of PM2.5 in the air is an indicator that people are generally concerned about. Therefore, the average annual air PM2.5 concentration was selected as the calculation factor driven by the environmental protection requirements. The higher the average air PM2.5 concentration, the greater the potential for electrical energy replacement.

(3) Number of Motor Vehicles. Without considering the energy consumption of the whole life cycle, from the view of the car alone, the electric car has a certain energy-saving effect. The larger the number of traditional fuel vehicles in a region, the greater the consumption of gasoline, diesel, and other energy sources, and the more favorable the promotion of electric vehicles, the greater the demand. As the largest industrial field in the world, the auto industry has a strong representativeness. Therefore, the choice of regional fuel vehicle ownership as a calculation factor is driven by the environmental protection carbon emission requirements; the more the number of vehicle ownership, the greater the potential for electrical energy substitution.

2.2.4. Economical Efficiency. Since the energy of alternative fossil energy is mainly electric energy and natural gas at this stage, the comparison of economic indicators is mainly the comparison between electric energy and natural gas. Under the economic indicators, it is divided into five secondary indexes: industrial gas price, residential gas price, residential electricity price, large industrial electricity price, and general industrial and commercial electricity price. Residential gas price and residential electricity price are mainly for decentralized electric heating, heat pumps, and electric cookers. Industrial gas price, large industrial electricity price, and general industrial and commercial electricity price are mainly aimed at electric boiler heating, building materials kilns and intermediate frequency furnaces. The general idea is that the lower the price of electricity in an area, the greater the potential for electrical energy replacement in the area; the lower the price of natural gas, the greater the resistance to competition for electrical energy replacement in the region and the lower the potential for electrical energy replacement.

2.2.5. Supporting Support. At present, the development of electrical energy substitution is inseparable from supporting policies, under the criteria of supporting support, including two indicators: supporting policies and power surplus and deficiency.
(1) Support Policies. Support policies are divided into environmental protection policies, electricity price subsidy policies, and planning policies. Strict environmental protection policies are conducive to promoting the development of electrical energy substitution; electricity price subsidy policies are conducive to the electrical energy substitution to obtain cost advantages and strive for users; planning policies (electric vehicles, distribution network construction, etc.) are conducive to the development of electrical energy substitution related industries; the more the support policies in a region, the greater the potential for electrical energy substitution.

(2) Electricity Surplus and Shortage. The degree of electricity surplus and deficiency in the region determines the enthusiasm for promoting electric energy substitution, so the greater the surplus of electric, the greater the potential for electric energy substitution.

\section{China's Regional Electrical Energy Substitution Potential Evaluation Model}

3.1. Cloud Model. The cloud model was proposed by $\mathrm{Li}$ Deyi, academician of the Chinese Academy of Engineering in 1995. It is an uncertain transformation model that deals with qualitative concepts and quantitative descriptions. Since its introduction, it has been successfully applied to prediction [18], reliability analysis [19], data mining [20], system index testing [21], intelligent algorithm optimization [22], marketing [23], multicriteria decision making [24, 25], and so on.

The cloud is defined this way [26], assuming that $U$ is a quantitative domain of expression with exact numerical values, $X \subseteq U$, and $\mathrm{T}$ is a qualitative concept in $\mathrm{U}$ space. If there is a stable random number $C_{T}(x) \in[0,1]$ for the element $x(x \in X)$, this is called the degree of membership of $\mathrm{x}$ to T, i.e., $C_{T}(x): U \longrightarrow[0,1], \forall_{x} \in X(X \subseteq U), x \longrightarrow$ $C_{T}(x)$, the distribution of the concept $\mathrm{T}$ from the universe $\mathrm{U}$ to the interval $[0,1]$ in the domain space is called the cloud, and each $x$ is called the cloud drop. The cloud model can be represented by the three numerical characteristics of expected value, entropy, and hyperentropy, which are, respectively, denoted as $E x, E n$, and $H e$. The expected value $E x$ is the position of the center of gravity of all cloud droplets in the number domain, that is, the coordinates that best represent this qualitative concept in the number domain. Entropy En is a measure of the concept of qualitative as well as another, that is, the range of values that can be accepted by this qualitative concept in the number domain, and also reflects the probability that these points in the number domain can represent this qualitative concept. Hyperentropy $\mathrm{He}$ is the degree of entropy En dispersion, that is, the entropy of entropy. It reflects the degree of aggregation of each value representing the degree of certainty of the qualitative concept and also reflects the degree of condensation of cloud droplets. Usually, the cloud model can be written as $C(E x, E n, H e)$, and in the theoretical research and practical application of the cloud model, the main focus is on normal clouds, especially one-dimensional normal clouds. 
TABLE 2: Language evaluation variables and corresponding cloud models.

\begin{tabular}{lc}
\hline Language evaluation variable & Cloud model \\
\hline Very Low & $(0.165,0.055,0.0262)$ \\
Low & $(0.335,0.055,0.0162)$ \\
Medium & $(0.5,0.0567,0.01)$ \\
High & $(0.665,0.055,0.0162)$ \\
Very High & $(0.835,0.055,0.0262)$ \\
\hline
\end{tabular}

3.1.1. One-Dimensional Normal Cloud Approximate Representation of Language Evaluation Scale. When the guideline value is a random variable that obeys the normal distribution $N\left(\mu, \sigma^{2}\right)$, when the decision maker cannot learn more information, the guideline value can be approximated as a random variable that falls within the interval $[a, b]$, where

$$
\begin{aligned}
& a=\mu-k \sigma, \\
& b=\mu+k \sigma
\end{aligned}
$$

Usually, $k \geq 2$; this paper takes $\mathrm{k}=3[27]$.

When the corresponding numerical range of the linguistic evaluation scale on a given domain is determined and the corresponding numerical membership degree is uncertain, the uncertain linguistic evaluation scale can be converted into an approximate one-dimensional normal cloud processing. After converting the linguistic evaluation scale in a given domain into interval numbers, the interval number is converted to an approximate one-dimensional normal random number using (1) to obtain the approximate one-dimensional normal cloud expectation $E x$ and entropy $\mathrm{En}$. The hyperentropy $\mathrm{He}$ of the one-dimensional normal cloud is determined according to the uncertainty degree of the language evaluation scale. If you only know the degree of uncertainty of the central language evaluation scale (corresponding to the hyperentropy of the one-dimensional normal cloud is $\mathrm{He}_{0}$ ), you can use the golden section rate method to approximately obtain the uncertainty of other language evaluation scales. The basic idea is that if the uncertainty language evaluation scale in a given domain is expressed by a cloud model, then the closer the hyperentropy of the cloud to the center of the domain, the smaller the hyperentropy. For the hyperentropy of adjacent clouds, the cloud closer to the center of the domain is 0.618 times that of the cloud far to the center of the domain.

In this paper, five language evaluation scales are transformed into five one-dimensional normal clouds in the domain $[0,1]$ (set according to the degree of uncertainty of the language evaluation scale $\mathrm{He}_{0}=0.01$ ).The five language evaluation scales are \{very low, low, medium, high, very high $\}$, denoted as $\{\mathrm{VL}, \mathrm{L}, \mathrm{M}, \mathrm{H}, \mathrm{VH}\}$. The interval number corresponding to the language evaluation scale is $\{[0,0.33],[0.17,0.5],[0.33,0.67],[0.5,0.83],[0.67,1]\}$. Therefore, the one-dimensional normal cloud corresponding to each language evaluation scale is shown in Table 2.

3.1.2. Cloud Synthesis. Cloud synthesis is the process of superimposing two cloud models to obtain a comprehensive cloud model. Assume that $C_{1}=\left(E x_{1}, E n_{1}, H e_{1}\right), C_{2}=\left(E x_{2}\right.$, $\left.E n_{2}, H e_{2}\right)$ are two cloud models; $a$ and $b$ are two constants. According to the independent normal distribution algorithm, the synthesis algorithm of the integrated cloud is

$$
\begin{aligned}
a C_{1} & +b C_{2}=a\left(E x_{1}, E n_{1}, H e_{1}\right)+b\left(E x_{2}, E n_{2}, H e_{2}\right) \\
& =\left(a E x_{1}, a E n_{1}, a H e_{1}\right)+\left(b E x_{2}, b E n_{2}, b H e_{2}\right) \\
& =\left(a E x_{1}+b E x_{2}, \sqrt{\left(a E n_{1}\right)^{2}+\left(b E n_{2}\right)^{2}}\right. \\
& \left.\sqrt{\left(a H e_{1}\right)^{2}+\left(b H e_{2}\right)^{2}}\right)
\end{aligned}
$$

3.2. Calculation of Each Index Weight. According to the different sources of the original data when calculating the weights, the method of determining the weights can be divided into three categories: subjective weighting method, objective weighting method, and combination weighting method. The subjective weighting method can reasonably determine the ranking of each attribute weight based on the actual decision problems and the expert's own knowledge and experience. There will be no situation where the attribute weights are inconsistent with the actual importance of the attributes. However, decision-making or evaluation results have strong subjective arbitrariness. The objective weighting method is mainly based on the relationship between the original data to determine the weight, so the objectivity of the weight is strong; the method has a strong mathematical theory basis. However, this weighting method does not consider the subjective intention of the decision makers. Therefore, the determined weights may not be consistent with people's subjective wishes or actual conditions. For the advantages and disadvantages of the subjective and objective weighting methods, in order to take into account the preferences of the decision makers on attributes and at the same time strive to reduce the subjective randomness of weighting, so that the weight of the attribute is to achieve subjective and objective unity and then make the decision-making results true and reliable. Therefore, a reasonable method of weighting should include both the inherent laws of indicator data and the judgement of expert experience on decision indicators. So, this paper adopts the third method of weighting, that is, subjective and objective comprehensive weighting method, or combination weighting method, to determine the weights of each index.

Assuming that the object to be evaluated is $A_{i}(i=$ $1,2,3 \ldots, m)$ and the evaluation index is $C_{\mathrm{j}}(j=1,2,3 \ldots, n)$, an expert group composed of s experts $P_{k}(k=1,2,3 \ldots, s)$ will evaluate the importance of each evaluation index. According to Table 2, the evaluation language is transformed into the corresponding cloud model $Z_{j}^{k}=\left(E x_{z j}^{k}, E n_{z j}^{k}, H e_{z j}^{k}\right)$. The cloud models are given by the different expert after conversion are synthesized according to formula (2), and the cluster cloud evaluation models of the corresponding index are calculated, and its calculation formula is

$$
Z_{j}=\frac{1}{s} \times \sum_{k=1}^{s} Z_{j}^{k}
$$


Letting the cloud model $Z^{*}$ with a very high scale of language evaluation $(\mathrm{VH})$ as a cloud with an importance degree of 1 , calculating the similarity $\operatorname{sim}\left(Z_{j}, Z^{*}\right)$ between $Z_{j}$ and $Z^{*}$ according to the similarity calculation method of cloud in [28] using $Z^{*}$ as the reference cloud, the higher the degree of similarity, the higher the degree of importance; on the contrary, the smaller the degree of similarity, the lower the degree of importance. Normalize $\operatorname{sim}\left(Z_{j}, Z^{*}\right)$ and then calculate the initial subjective weight of each evaluation index as [29]

$$
r_{j}=\frac{\operatorname{sim}\left(Z_{j}, Z^{*}\right)}{\sum_{j=1}^{n} \operatorname{sim}\left(Z_{j}, Z^{*}\right)}
$$

In order to reflect the objectivity of each quantitative index, the initial objective weight $\lambda_{j}$ of each evaluation index is calculated according to the entropy weight method. Based on a comprehensive consideration of subjective and objective, the weight of each indicator is defined as follows:

$$
\omega_{j}=\frac{1}{2} \times r_{j}+\frac{1}{2} \times \lambda_{j}
$$

\subsection{TOPSIS Comprehensive Evaluation Model Based on Con- nection Degree Optimization}

3.3.1. Set Pair Analysis and Connection Degree. The core idea of set pair analysis is taking deterministic uncertainty as a certain and uncertain system. In this system, certainty and uncertainty are interconnected, mutually influenced, mutually constrained, and converted to each other under certain conditions [30]. Set pair analysis adopts a connection degree that can fully reflect the above-mentioned ideas to uniformly describe the various uncertainties caused by incompleteness of fuzzy, random, intermediary, and incomplete information, thereby transforming the dialectical understanding of uncertainty into concrete mathematical operations.

Supposing the set pair $H=\left(A_{0}, B_{1}\right)$ is composed of the set $A_{0}=\left\{x_{01}, x_{02}, \ldots, x_{0 n}\right\}$ and the set $B_{1}=\left\{x_{11}, x_{12}, \ldots\right.$, $\left.x_{1 n}\right\}$. Comparing the $\mathrm{n}$ corresponding items of $A_{0}$ and $B_{1}$, there is a small difference in the number of $s$ items, and there is a great difference in the number of $\mathrm{p}$ items. The remaining $f=n-s-p$ items have some differences in quantity, but the disparity is not obvious. If the difference is small, they are considered to be the same, and the difference is big, they are considered to be opposite. If there is a certain difference, it is considered to be a difference. Thus, the set pair relationship consisting of $A_{0}$ and $B_{1}$ is transformed into the same, different, and opposite relationship. The connection degree of the uncertain quantitative relationship between sets $A_{0}$ and $B_{1}$ can be expressed as

$$
\mu\left(A_{0}-B_{1}\right)=a+b i+c j=\frac{s}{N}+\frac{f}{N} i+\frac{p}{N} j
$$

where $a+b+c=1, i$ is the difference mark symbol or the corresponding coefficient, and the value varies depending on the condition in the $[-1,1]$ interval. $j$ is the opposite sign or the corresponding coefficient and its value is -1 .
3.3.2. Improved TOPSIS Model by Connection Degree. TOPSIS method has many characteristics such as easy to understand, simple calculation, reasonable evaluation result, and more flexible application. It has been widely used in social economy, engineering, and other fields. However, the TOPSIS method also has its shortcomings: when an object's Euclidean distance with the ideal point is small, its Euclidean distance with the negative ideal point may be small too. The result of sorting the evaluation object by the relative Euclidean distance sometimes cannot completely reflect the good and bad of each evaluation object. In order to overcome these shortcomings, literature [31] considers the ideal and negative ideal points as mutually opposite sets in the certain uncertain system. When calculating the connection degree between the object to be evaluated and the ideal or negative ideal point fully considered the existence of the opposite set, through the introduction of the concept of connect vector distance, calculate the relative close degree. TOPSIS method improved by connection degree has properties of if the distance between the evaluation object and the ideal point is closer, the distance between the evaluation object and the negative ideal point is farther away and vice versa. This paper applies the TOPSIS method improved by connection degree to evaluate China's regional electrical energy substitution potential. Compared with other methods, this method has the following advantages:

(1) The final evaluation value can be combined with the classification of categories to not only determine the category to which each evaluation area belongs, but also compare the difference in evaluation potential between different regions.

(2) Improved TOPSIS method that can simultaneously evaluate multiple objects and then sort. It has the characteristics of fast calculation, high resolution, objective evaluation, better rationality, and applicability and has a high practical value.

Supposing that there are $m$ objects to be evaluated $P_{1}, P_{2}, \ldots, P_{\mathrm{m}}$ and $\mathrm{n}$ indicators $X_{1}, X_{2}, \ldots, X_{n}, x_{i j}$ is the index value of $P_{i}$ under indicator $X_{j},(i=1,2, \ldots, m, j=$ $1,2, \ldots, n)$, and $\omega_{j}$ is the weight of indicator $X_{j}, \omega_{j} \in[0,1]$, and $\sum_{j=1}^{n} \omega_{j}=1$. The calculation steps of the TOPSIS method based on connection degree optimization are as follows [32]:

(1) $X=\left(x_{i j}\right)_{m \times n}$ and $\omega_{j}$ form an initialization decision matrix.

(2) Determine the ideal point $S^{+}$and negative ideal point $S^{-}$

$$
\begin{aligned}
& S^{+}=\left\{s_{j}^{+} \mid j=1,2, \ldots, n\right\}, \\
& S^{-}=\left\{s_{j}^{-} \mid j=1,2, \ldots, n\right\}
\end{aligned}
$$

When $X_{j}$ is a positive indicator, $S^{+}=\max _{1 \leq i \leq m}\left\{x_{i j}\right\}$ and $S^{-}=\min _{1 \leq i \leq m}\left\{x_{i j}\right\}$. When $X_{j}$ is a negative indicator, $S^{+}=$ $\operatorname{minx}_{1 \leq i \leq m}\left\{x_{i j}\right\}, S^{-}=\max _{1 \leq i \leq m}\left\{x_{i j}\right\}$. When $X_{1}, X_{2}, \ldots, X_{n}$ are all positive indicators, the method for calculating the connection degree between each object to be evaluated and the ideal point and the negative ideal point follow the below step.

(3) Calculate the connection degree $u_{k}^{+}$between the object $P_{k}$ to be evaluated and the ideal point $S^{+}$. 
A set pair $H^{+}=\left(P_{k}, S^{+}\right)$is composed of the object $P_{k}$ to be evaluated and the ideal point $S^{+}$. Then

$$
\begin{aligned}
& u_{k}^{+}=a_{k}^{+}+b_{k}^{+} i+c_{k}^{+} j=\omega_{1} u_{k 1}^{+}+\omega_{2} u_{k 2}^{+}+\cdots+\omega_{n} u_{k n}^{+} \\
& =\sum_{t=1}^{n} \omega_{t} u_{k t}^{+} \\
& u_{k t}^{+}=a_{k t}^{+}+b_{k t}^{+} i+c_{k t}^{+} j \text {, } \\
& k=1,2, \ldots, m ; t=1,2, \ldots, n
\end{aligned}
$$

where when $x_{k t}=s_{t}^{-}$, then $a_{k t}^{+}+b_{k t}^{+}=0, c_{k t}^{+}=1$; when $x_{k t} \in$ $\left(s_{t}^{-}, s_{t}^{+}\right]$, then $a_{k t}^{+}=x_{k t} / s_{t}^{+}, b_{k t}^{+}=1-a_{k t}^{+}, c_{k t}^{+}=0$.

(4) Calculate the connection degree $u_{k}^{-}$between the object $P_{k}$ to be evaluated and the negative ideal point $S^{-}$.

A set pair $H^{-}=\left(P_{k}, S^{-}\right)$is composed of the object $P_{k}$ to be evaluated and the negative ideal point $S^{-}$. Then

$$
\begin{aligned}
u_{k}^{-} & =a_{k}^{-}+b_{k}^{-} i+c_{k}^{-} j=\omega_{1} u_{k 1}^{-}+\omega_{2} u_{k 2}^{-}+\cdots+\omega_{n} u_{k n}^{-} \\
& =\sum_{t=1}^{n} \omega_{t} u_{k t}^{-}
\end{aligned}
$$

$$
u_{k t}^{-}=a_{k t}^{-}+b_{k t}^{-} i+c_{k t}^{-} j,
$$

$$
k=1,2, \ldots, m ; t=1,2, \ldots, n
$$

where when $x_{k t}=s_{t}^{+}$, then $a_{k t}^{-}+b_{k t}^{-}=0, c_{k t}^{-}=1$; when $x_{k t} \epsilon$ $\left[s_{t}^{-}, s_{t}^{+}\right)$, then $a_{k t}^{-}=s_{t}^{-} / x_{k t}, b_{k t}^{-}=1-a_{k t}^{-}, c_{k t}^{-}=0$.

In particular, when $s_{t}^{-}=0, x_{k t}=0$, then $a_{k t}^{-}=1, b_{k t}^{-}=$ $c_{k t}^{-}=0$; when $s_{t}^{-}=0, x_{k t} \neq 0$, then $a_{k t}^{-}=\left(s_{t}^{+}-\right.$ $\left.x_{k t}\right) / s_{t}^{+}, b_{k t}^{-}=1-a_{k t}^{-}, c_{k t}^{-}=0$.When there are negative indexes in $X_{1}, X_{2}, \ldots, X_{n}$, the connection degrees between the index value and the corresponding index value of the ideal point are calculated according to formula (9) principle, and the connection degrees between the index value and the corresponding index value of the negative ideal point are calculated according to formula (8) principle.

(5) The distance between the object vector $P_{k}$ to be evaluated and the connection vector of the ideal point $S^{+}$is calculated.

The connection vector of the ideal point $S^{+}$is $\overrightarrow{u^{+}}=$ $(1,0,0)$, and the corresponding connection vector of the object $P_{k}$ to be evaluated is $\overrightarrow{u^{+}}=\left(a_{k}^{+}, b_{k}^{+}, c_{k}^{+}\right)$, then the distance between the connection vector of $P_{k}$ and $S^{+}$is

$$
d_{k}^{+}=\sqrt{\left(1-a_{k}^{+}\right)^{2}+\left(b_{k}^{+}\right)^{2}+\left(b_{k}^{+}\right)^{2}}
$$

(6) The distance between the object vector $P_{k}$ to be evaluated and the connection vector of the negative ideal point $S^{-}$is calculated.

The connection vector of the negative ideal point $S^{-}$is $\overrightarrow{u^{-}}=(-1,0,0)$, and the corresponding connection vector of the object $P_{k}$ to be evaluated is $\overrightarrow{u^{-}}=\left(a_{k}^{-}, b_{k}^{-}, c_{k}^{-}\right)$, then the distance between the connection vector of $P_{k}$ and $S^{-}$is

$$
d_{k}^{-}=\sqrt{\left(1-a_{k}^{-}\right)^{2}+\left(b_{k}^{-}\right)^{2}+\left(b_{k}^{-}\right)^{2}}
$$

(7) Calculate the close degree of the object $P_{k}$ to be evaluated and the ideal point $S^{+}$.

$$
c_{k}=\frac{d_{k}^{-}}{d_{k}^{-}+d_{k}^{+}}, \quad k=1,2, \ldots, m
$$

The larger $c_{k}$, the closer the object $P_{k}$ to the ideal point and vice versa.

\section{Case Study}

Taking the twenty-five provinces and cities within the jurisdiction of the State Grid as an example, the potential for electrical energy substitution in each province and city is evaluated. The raw data of its indicators are shown in Table 3. The energy consumption and the price of energy of each province and city come from the statistical yearbooks of various provinces and cities and the national power price supervision notification. Among them, the policy support intensity data is transformed from the combination of the number of relevant policy documents issued by the various regions in the past two years and the expert's evaluation of policy support for provinces and cities.

\subsection{Calculation of Electrical Energy Substitution Potential} Evaluation Index Weights. According to the method described above, the calculation steps are as follows.

(1) Determining Experts' Evaluation Results for Each Indicator. Since this paper does not involve real projects, therefore, the results of expert evaluation are simulated by simulating the relevant steps of expert evaluation. The steps for simulating expert evaluation results are as follows: (1) Selecting five people who are more familiar with this field. (2) Providing the five personnel with the sixteen evaluation indicators and evaluation language scales and other relevant materials selected in this paper. (3) Asking five people to evaluate the importance of each indicator according to \{very low, low, medium, high, very high\} five language evaluation scales. (4) Organizing and summarizing the evaluation results of the five personnel. Based on the above steps, the simulation results of experts in this paper are shown in Table 4.

(2) Calculating Index Initial Subjective Weights. According to the language evaluation of each indicator by five experts, according to the transformation relationship between language evaluation and cloud model in Table 1, the evaluation languages are converted into the corresponding cloud models. According to formula (2), different cloud models of the same index are synthesized, and a group evaluation cloud model $Z_{j}$ of each index is obtained according to formula (3). Let $Z^{*}=(0.835,0.055,0.0262)$ as a benchmark cloud with significance degree is 1 and calculate the similarity $\operatorname{sim}\left(Z_{j}, Z^{*}\right)$ between $Z_{j}$ and $Z^{*}$, and normalize $\operatorname{sim}\left(Z_{j}, Z^{*}\right)$ according to formula (4) to obtain the initial subjective weight $r_{j}$ of each index. The results are shown in Table 5.

(3) Determination of Index Weights. Calculating the initial objective weight $\lambda_{j}$ of each evaluation index according to the 
TABLE 3

(a) Initial values of evaluation indicators for each region

\begin{tabular}{|c|c|c|c|c|c|c|}
\hline Area & $\begin{array}{c}\text { GDP }(10,000 \\
\text { yuan })\end{array}$ & $\begin{array}{c}\text { Population } \\
(10,000)\end{array}$ & $\begin{array}{c}\text { Coal } \\
\text { consumption } \\
(10,000 \text { tons })\end{array}$ & $\begin{array}{l}\text { Crude oil } \\
\text { consumption } \\
\text { (10,000 tons) }\end{array}$ & $\begin{array}{c}\text { Natural gas } \\
\text { consumption (100 } \\
\text { million cubic meters) }\end{array}$ & $\begin{array}{c}\text { Electricity } \\
\text { consumption }(100 \\
\text { million } \mathrm{kWh})\end{array}$ \\
\hline Beijing & 25669.13 & 2173 & 1165.18 & 991.54 & 146.88 & 952.72 \\
\hline Shanghai & 28178.65 & 2420 & 4728.13 & 2526.11 & 77.41 & 1405.6 \\
\hline Tianjin & 17885.39 & 1562 & 4538.83 & 1616.72 & 63.98 & 800.6 \\
\hline Chongqing & 17740.59 & 3048 & 6047.19 & 704.33 & 88.37 & 875.37 \\
\hline Sichuan & 32934.54 & 8262 & 9288.9 & 989.56 & 170.98 & 1992.4 \\
\hline Hebei & 32070.45 & 7470 & 28943.1 & 1666.82 & 72.97 & 3175.7 \\
\hline Shanxi & 13050.41 & 3682 & 37115.1 & 746.91 & 64.92 & 1737.2 \\
\hline Shandong & 68024.49 & 9947 & 40926.9 & 8607.02 & 82.32 & 5117.1 \\
\hline Jiangsu & 77388.28 & 7999 & 27209.1 & 3823.2 & 165.02 & 5114.7 \\
\hline Zhejiang & 47251.36 & 5590 & 13826 & 2846.84 & 80.35 & 3553.9 \\
\hline Anhui & 24407.62 & 6196 & 15671.3 & 690.59 & 34.83 & 1639.8 \\
\hline Fujian & 28810.58 & 3874 & 7659.94 & 2164.85 & 45.38 & 1851.9 \\
\hline Hubei & 32665.38 & 5885 & 11765.9 & 1299.01 & 40.26 & 1665.2 \\
\hline Hunan & 31551.37 & 6822 & 11142.2 & 878.46 & 26.51 & 1447.6 \\
\hline Henan & 40471.79 & 9532 & 23719.9 & 847.26 & 78.77 & 2879.6 \\
\hline Jiangxi & 18499 & 4592 & 7698.24 & 555.96 & 18.02 & 1087.3 \\
\hline Liaoning & 22246.9 & 4378 & 17336.4 & 6439.87 & 55.35 & 1984.9 \\
\hline Shaanxi & 19399.59 & 3813 & 18373.6 & 2101.1 & 82.69 & 1221.7 \\
\hline Gansu & 7200.37 & 2610 & 6557.06 & 1446.5 & 26.04 & 1098.7 \\
\hline Ningxia & 3168.59 & 675 & 8907.37 & 477.12 & 20.65 & 878.33 \\
\hline Xinjiang & 9649.7 & 2398 & 17359.3 & 2489.49 & 145.84 & 2160.3 \\
\hline Heilongjiang & 15386.09 & 3799 & 13432.9 & 2123.9 & 35.82 & 868.97 \\
\hline Inner Mongolia & 18128.1 & 2520 & 36499.8 & 383.67 & 39.15 & 2542.9 \\
\hline Qinghai & 2572.49 & 593 & 1508.12 & 154.33 & 44.38 & 658 \\
\hline Jilin & 14776.8 & 2733 & 9805.31 & 960.34 & 21.34 & 651.96 \\
\hline
\end{tabular}

(b) Initial values of evaluation indicators for each region

\begin{tabular}{|c|c|c|c|c|c|}
\hline Area & $\begin{array}{l}\text { Annual scattered } \\
\text { coal consumption } \\
\quad(10,000 \text { tons })\end{array}$ & $\begin{array}{c}\text { Annual air PM2.5 } \\
\text { average } \\
\text { concentration } \\
\left(\mathrm{ug} / \mathrm{m}^{3}\right)\end{array}$ & $\begin{array}{l}\text { Number of motor } \\
\text { vehicles (unit) }\end{array}$ & $\begin{array}{c}\text { Industrial gas } \\
\text { price (yuan/cubic } \\
\text { meter) }\end{array}$ & $\begin{array}{c}\text { Residential gas } \\
\text { price (yuan/cubic } \\
\text { meter) }\end{array}$ \\
\hline Beijing & 767.8 & 72.5 & 5671347 & 3.65 & 2.28 \\
\hline Shanghai & 0 & 45 & 3727555 & 3.79 & 3.05 \\
\hline Tianjin & 232.8 & 68.8 & 2848854 & 3.25 & 2.4 \\
\hline Chongqing & 326.8 & 54.2 & 5151736 & 2.84 & 1.72 \\
\hline Sichuan & 318.8 & 62.9 & 15007940 & 3.25 & 1.89 \\
\hline Hebei & 2525.2 & 98.8 & 18170618 & 3.8 & 2.4 \\
\hline Shanxi & 2587.3 & 66.1 & 6218106 & 3.6 & 2.26 \\
\hline Shandong & 2021.3 & 75.6 & 25104790 & 4.14 & 2.7 \\
\hline Jiangsu & 321.3 & 47.9 & 18666017 & 3.65 & 2.2 \\
\hline Zhejiang & 343 & 48.9 & 16777770 & 4.84 & 2.4 \\
\hline Anhui & 482.4 & 57.2 & 12068657 & 2.33 & 2.33 \\
\hline Fujian & 87.2 & 27.4 & 9492548 & 3.42 & 3.65 \\
\hline Hubei & 1339.1 & 57.1 & 11038649 & 3.41 & 2.53 \\
\hline Hunan & 1872.1 & 53.7 & 11790367 & 3.88 & 2.45 \\
\hline Henan & 1967.4 & 78.3 & 21504977 & 3.23 & 2.25 \\
\hline
\end{tabular}


(b) Continued.

\begin{tabular}{|c|c|c|c|c|c|}
\hline Area & $\begin{array}{l}\text { Annual scattered } \\
\text { coal consumption } \\
\quad(10,000 \text { tons })\end{array}$ & $\begin{array}{c}\text { Annual air PM2.5 } \\
\text { average } \\
\text { concentration } \\
\left(\mathrm{ug} / \mathrm{m}^{3}\right)\end{array}$ & $\begin{array}{l}\text { Number of motor } \\
\text { vehicles (unit) }\end{array}$ & $\begin{array}{c}\text { Industrial gas } \\
\text { price (yuan/cubic } \\
\text { meter) }\end{array}$ & $\begin{array}{l}\text { Residential gas } \\
\text { price (yuan/cubic } \\
\text { meter) }\end{array}$ \\
\hline Jiangxi & 1133.1 & 43.4 & 6801924 & 3.44 & 3.2 \\
\hline Liaoning & 1031.2 & 53 & 8317637 & 3.9 & 3.3 \\
\hline Shaanxi & 1783.7 & 71.4 & 6532087 & 2.3 & 1.98 \\
\hline Gansu & 825.5 & 53.9 & 6012074 & 2.64 & 1.7 \\
\hline Ningxia & 159.3 & 54.9 & 1960797 & 2.24 & 1.9 \\
\hline Xinjiang & 1123.8 & 72.9 & 4840614 & 2.11 & 1.37 \\
\hline Heilongjiang & 2455 & 50.9 & 4970344 & 4.3 & 2.8 \\
\hline Inner Mongolia & 3062.6 & 40.3 & 5779153 & 2 & 1.82 \\
\hline Qinghai & 183.5 & 49.2 & 1118458 & 1.7 & 1.48 \\
\hline Jilin & 809.4 & 45.8 & 5172885 & 2.8 & 2.8 \\
\hline
\end{tabular}

(c) Initial values of evaluation indicators for each region

\begin{tabular}{|c|c|c|c|c|c|}
\hline Area & $\begin{array}{c}\text { Residential } \\
\text { electricity price } \\
\text { (yuan/kWh) }\end{array}$ & $\begin{array}{l}\text { Large industrial } \\
\text { electricity price } \\
\text { (yuan/kWh) }\end{array}$ & $\begin{array}{c}\text { General } \\
\text { industrial and } \\
\text { commercial } \\
\text { electricity } \\
\text { price } \\
\text { (yuan/kWh) }\end{array}$ & $\begin{array}{l}\text { Support } \\
\text { policies }\end{array}$ & $\begin{array}{c}\text { Electricity } \\
\text { surplus and } \\
\text { deficiency } \\
\text { (million } \\
\text { kilowatts) }\end{array}$ \\
\hline Beijing & 0.488 & 0.635 & 0.8595 & 1 & 49.45 \\
\hline Shanghai & 0.617 & 0.804 & 0.899 & 0.8 & 423.27 \\
\hline Tianjin & 0.49 & 0.6759 & 0.8686 & 1 & 82.78 \\
\hline Chongqing & 0.52 & 0.6198 & 0.8055 & 1 & 465.2 \\
\hline Sichuan & 0.522 & 0.5394 & 0.8384 & 2 & 507.84 \\
\hline Hebei & 0.52 & 0.5126 & 0.676 & 1 & 0.1826 \\
\hline Shanxi & 0.477 & 0.4942 & 0.6763 & 0.8 & 1202.69 \\
\hline Shandong & 0.547 & 0.6024 & 0.7489 & 1 & 896.85 \\
\hline Jiangsu & 0.528 & 0.6151 & 0.8289 & 0.8 & 454.32 \\
\hline Zhejiang & 0.538 & 0.6396 & 0.8549 & 0.8 & 583.9 \\
\hline Anhui & 0.565 & 0.6074 & 0.8084 & 1 & 490.54 \\
\hline Fujian & 0.498 & 0.5622 & 0.7573 & 1 & 644.55 \\
\hline Hubei & 0.558 & 0.5748 & 0.86 & 0.8 & 637.27 \\
\hline Hunan & 0.588 & 0.6112 & 0.8577 & 0.8 & 515.55 \\
\hline Henan & 0.56 & 0.5912 & 0.7355 & 2 & 650.59 \\
\hline Jiangxi & 0.6 & 0.6187 & 0.7652 & 1 & 201.62 \\
\hline Liaoning & 0.5 & 0.5096 & 0.8203 & 0.8 & 630.92 \\
\hline Shaanxi & 0.498 & 0.5351 & 0.7934 & 1 & 101.7 \\
\hline Gansu & 0.51 & 0.4556 & 0.7788 & 0.8 & 611.53 \\
\hline Ningxia & 0.449 & 0.388 & 0.6654 & 0.8 & 273.69 \\
\hline Xinjiang & 0.469 & 0.35 & 0.516 & 0.8 & 2011.51 \\
\hline Heilongjiang & 0.51 & 0.558 & 0.863 & 0.8 & 669.35 \\
\hline Inner Mongolia & 0.5 & 0.495 & 0.79 & 0.8 & 650.45 \\
\hline Qinghai & 0.377 & 0.3622 & 0.6501 & 0.8 & 602.07 \\
\hline Jilin & 0.525 & 0.5486 & 0.884 & 0.8 & 637.52 \\
\hline
\end{tabular}


TABLE 4: Linguistic evaluation of importance for evaluation indicators by five experts.

\begin{tabular}{|c|c|c|c|c|c|}
\hline Evaluation index & Very Low & Low & Medium & High & Very High \\
\hline GDP & 0 & 1 & 4 & 0 & 0 \\
\hline Population & 1 & 1 & 2 & 1 & 0 \\
\hline Coal consumption & 0 & 0 & 0 & 2 & 3 \\
\hline Crude oil consumption & 0 & 0 & 1 & 2 & 2 \\
\hline Natural gas consumption & 0 & 0 & 1 & 3 & 1 \\
\hline Electricity consumption & 0 & 1 & 3 & 1 & 0 \\
\hline Annual scattered coal consumption & 0 & 0 & 1 & 1 & 3 \\
\hline Annual air PM2.5 average concentration & 0 & 0 & 0 & 3 & 2 \\
\hline Number of motor vehicles & 0 & 1 & 4 & 0 & 0 \\
\hline Industrial gas price & 0 & 0 & 1 & 3 & 1 \\
\hline Residential gas price & 0 & 0 & 4 & 1 & 0 \\
\hline Residential electricity price & 0 & 0 & 2 & 3 & 0 \\
\hline Industrial electricity price & 0 & & 1 & 2 & 2 \\
\hline General industrial and commercial electricity price & 0 & 1 & 3 & 1 & 0 \\
\hline Support policies & 0 & 0 & 1 & 0 & 4 \\
\hline Electricity surplus and deficiency & 0 & 1 & 2 & 2 & 0 \\
\hline
\end{tabular}

TABLE 5: Clusters evaluation cloud model and initial subjective weight of each index.

\begin{tabular}{|c|c|c|c|}
\hline Index & $Z_{j}$ & $\operatorname{sim}\left(Z_{j}, Z^{*}\right)$ & $r_{j}$ \\
\hline GDP & $(0.467,0.0467,0.0086)$ & 2.7174 & 0.027 \\
\hline Population & $(0.433,0.0296,0.0462)$ & 2.4876 & 0.025 \\
\hline Coal consumption & $(0.767,0.0397,0.017)$ & 14.7059 & 0.146 \\
\hline Crude oil consumption & $(0.7,0.0331,0.0125)$ & 7.4074 & 0.074 \\
\hline Natural gas consumption & $(0.666,0.0366,0.0112)$ & 5.9172 & 0.059 \\
\hline Electricity consumption & $(0.5,0.0374,0.0075)$ & 2.9851 & 0.03 \\
\hline Annual scattered coal consumption & $(0.734,0.0366,0.0162)$ & 9.901 & 0.098 \\
\hline Annual air PM2.5 average concentration & $(0.733,0.0397,0.0143)$ & 9.8039 & 0.097 \\
\hline Number of motor vehicles & $(0.467,0.0467,0.0086)$ & 2.7174 & 0.027 \\
\hline Industrial gas price & $(0.666,0.0366,0.0112)$ & 5.9172 & 0.059 \\
\hline Residential gas price & $(0.533,0.0467,0.0086)$ & 3.3113 & 0.033 \\
\hline Residential electricity price & $(0.599,0.04,0.0105)$ & 4.2373 & 0.042 \\
\hline Industrial electricity price & $(0.7,0.0331,0.0125)$ & 7.4074 & 0.074 \\
\hline General industrial and commercial electricity price & $(0.5,0.0374,0.0075)$ & 2.9851 & 0.03 \\
\hline Support policies & $(0.768,0.0454,0.0211)$ & 14.9254 & 0.148 \\
\hline Electricity surplus and deficiency & $(0.533,0.0335,0.0083)$ & 3.3113 & 0.033 \\
\hline
\end{tabular}

entropy weight method and then determining the weight $\omega_{j}$ of each index according to formula (5), the results are shown in Table 6.

4.2. Evaluation of Electrical Energy Substitution Potential in Various Regions. This section uses the improved TOPSIS method by connection degree to assess the potential for electrical energy substitution in each region. The assessment steps are as follows:
(1) Constructing an initialization decision matrix based on the indicators' data in Table 3 and the indicators weights in Table 5.

(2) Determining the ideal point $S^{+}$and negative ideal point $S^{-}$.

$I_{1}, I_{2}, I_{3}, I_{4}, I_{6}, I_{7}, I_{8}, I_{9}, I_{10}, I_{11}, I_{15}, I_{16}$ are positive indicators, and $I_{5}, I_{12}, I_{13}, I_{14}$ are negative indicators. According to formula (7), ideal point $S^{+}$and negative ideal point $S^{-}$can be obtained.

$$
\begin{aligned}
& S^{+} \\
& \quad=\{77388.28,9947,40926.9,8607.02,18.02,5117.05,3062.6,98.8,25104790,4.84,3.65,0.3771,0.35,0.516,2,2011.51\} \\
& S^{-}=\{2572.49,593,1165.18,154.33,170.98,651.96,0,27.4,1118458,1.7,1.37,0.617,0.804,0.899,0.8,0.1826\}
\end{aligned}
$$


TABLE 6: Initial subjective weights, initial objective weights, and weight for each indicator.

\begin{tabular}{lccc}
\hline Index & $\mathrm{r}_{j}$ & $\lambda_{j}$ & $\omega_{j}$ \\
\hline GDP & 0.027 & 0.072 & 0.059 \\
Population & 0.025 & 0.087 & 0.042 \\
Coal consumption & 0.146 & 0.128 & 0.116 \\
Crude oil consumption & 0.074 & 0.065 & 0.101 \\
Natural gas consumption & 0.059 & 0.062 & 0.062 \\
Electricity consumption & 0.03 & 0.12 & 0.011 \\
Annual scattered coal consumption & 0.098 & 0.074 \\
Annual air PM2.5 average concentration & 0.097 & 0.01 & 0.109 \\
Number of motor vehicles & 0.027 & 0.01 & 0.054 \\
Industrial gas price & 0.059 & 0.002 \\
Residential gas price & 0.033 & 0.035 \\
Residential electricity price & 0.042 & 0.007 \\
Industrial electricity price & 0.074 & 0.003 \\
General industrial and commercial electricity price & 0.03 & 0.022 \\
Support policies & 0.148 & 0.03 \\
Electricity surplus and deficiency & 0.033 & 0.083 \\
\hline
\end{tabular}

(3) Calculating the connection degree.

According to (8) and (9), the connection degrees between each object to be evaluated and the ideal point and the negative ideal point are calculated. The calculation results are shown in Table 7.

(4) Calculating relative close degree.

According to (10) and (11), the distances between the object $P_{k}$ to be evaluated and the ideal point $S^{+}$and the negative ideal point $S^{-}$are calculated, then, according to formula (12), calculate the relative close degree of the object $P_{k}$ to be evaluated and the ideal point $S^{+}$. The calculation results are shown in Table 8.

\section{Result and Discussion}

From the calculation results in Table 8 , we can obtain the potential for electrical energy substitution in each region. According to the value of the electrical energy substitution potential, the sort order is Shandong $>$ Henan $>$ Hebei $>$ Sichuan $>$ Jiangsu $>$ Shanxi $>$ Shaanxi $>$ Inner Mongolia $>$ Liaoning $>$ Zhejiang $>$ Heilongjiang $>$ Hunan $>$ Hubei $>$ Anhui $>$ Xinjiang $>$ Fujian $>$ Jiangxi $>$ Beijing $>$ Shanghai $>$ Chongqing $>$ Tianjin $>$ Jilin $>$ Gansu $>$ Ningxia $>$ Qinghai.

The evaluation indexes that have the greatest impact on the potential for electrical energy replacement are the support policies, as shown in Figure 1, and the weight is 0.1784 , followed by coal consumption, annual scattered coal consumption, and crude oil consumption. The weights of these four evaluation indicators, regardless of whether it is the subjective evaluation of experts or the calculation based on entropy weight, are basically the four most weighted among all indicators. The sum of the weights of the four indicators is 0.5045 . Therefore, the size of these four indicators has a decisive effect on the size of the electrical energy substitution potential in a region. The index that has the greatest impact on the potential for electrical energy substitution is the

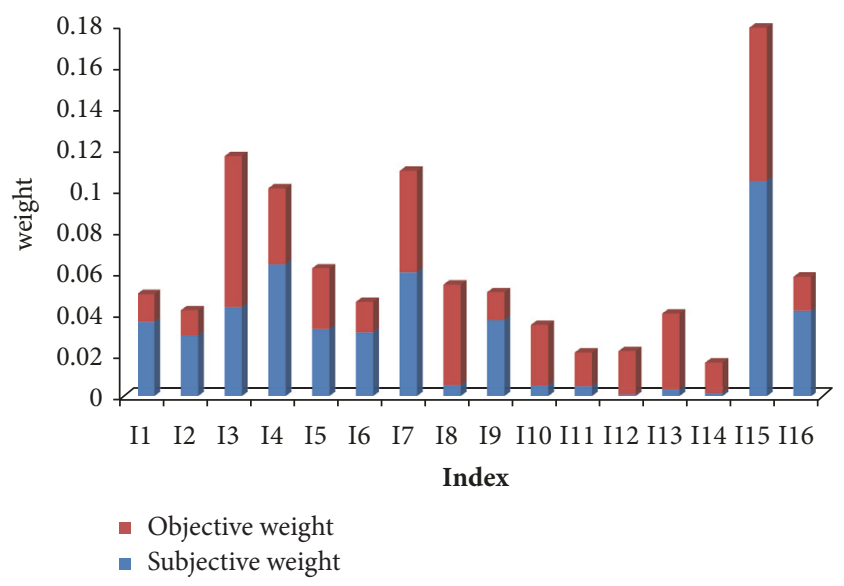

FIGURE 1: Initial subjective weights, initial objective weights, and weights for each index. Source of data in Figure 1: obtained from Table 6 with a subjective weight of $1 / 2 r_{j}$ and an objective weight of $1 / 2 \lambda_{j}$.

support policies; this is because the cost of using electricity is greater than the cost of using coal, natural gas, and other energy sources. Therefore, the enthusiasm of energy users to take the initiative to promote electrical energy substitution is not high. Only the government has introduced strict environmental protection policies and corresponding financial subsidies to promote the energy users to actively promote electrical energy substitution. Since electrical energy substitution is mainly used to replace fossil fuels such as coal and petroleum by electricity, the consumption of fossil energy is the basis for electrical energy substitution. Therefore, the three indicators of coal consumption, annual scattered coal consumption, and crude oil consumption have a relatively large weight, which is basically consistent with the reality. 
TABLE 7: The connection degrees between each object to be evaluated and the ideal point and the negative ideal point.

\begin{tabular}{|c|c|c|c|}
\hline No. & Evaluation object & $\mathrm{u}_{k}^{+}$ & $\mathrm{u}_{k}^{-}$ \\
\hline 1 & Beijing & $u_{1}^{+}=0.3719+0.5118 \mathrm{i}+0.1163 \mathrm{j}$ & $u_{1}^{-}=0.52+0.48 \mathrm{i}$ \\
\hline 2 & Shanghai & $u_{2}^{+}=0.2793+0.4332 \mathrm{i}+0.2875 \mathrm{j}$ & $u_{2}^{-}=0.4459+0.4758 \mathrm{i}+0.0783 j$ \\
\hline 3 & Tianjin & $u_{3}^{+}=0.3275+0.6725 \mathrm{i}$ & $u_{3}^{-}=0.4797+0.5203 \mathrm{i}$ \\
\hline 4 & Chongqing & $u_{4}^{+}=0.338+0.662 \mathrm{i}$ & $u_{4}^{-}=0.4716+0.5284 \mathrm{i}$ \\
\hline 5 & Sichuan & $u_{5}^{+}=0.5373+0.4627 \mathrm{i}$ & $u_{5}^{-}=0.2626+0.497 \mathrm{i}+0.2404 \mathrm{j}$ \\
\hline 6 & Hebei & $u_{6}^{+}=0.5756+0.3665 \mathrm{i}+0.0579 \mathrm{j}$ & $u_{6}^{-}=0.3522+0.5937 \mathrm{i}+0.0541 \mathrm{j}$ \\
\hline 7 & Shanxi & $u_{7}^{+}=0.4452+0.3764 \mathrm{i}+0.1784 \mathrm{j}$ & $u_{7}^{-}=0.3895+0.6105 \mathrm{i}$ \\
\hline 8 & Shandong & $u_{8}^{+}=0.765+0.235 \mathrm{i}$ & $u_{8}^{-}=0.2895+0.3557 \mathrm{i}+0.3548 \mathrm{j}$ \\
\hline 9 & Jiangsu & $u_{9}^{+}=0.5022+0.3194 i+0.1784 j$ & $u_{9}^{-}=0.4127+0.5377 \mathrm{i}+0.0495 \mathrm{j}$ \\
\hline 10 & Zhejiang & $u_{10}^{+}=0.3917+0.4299 \mathrm{i}+0.1784 \mathrm{j}$ & $u_{10}^{-}=0.4129+0.5525 \mathrm{i}+0.0346 \mathrm{j}$ \\
\hline 11 & Anhui & $u_{11}^{+}=0.3928+0.6072 \mathrm{i}$ & $u_{11}^{-}=0.4417+0.5583 \mathrm{i}$ \\
\hline 12 & Fujian & $u_{12}^{+}=0.3499+0.5961 \mathrm{i}+0.0541 \mathrm{j}$ & $u_{12}^{-}=0.455+0.5237 \mathrm{i}+0.0212 \mathrm{j}$ \\
\hline 13 & Hubei & $u_{13}^{+}=0.3463+0.4753 \mathrm{i}+0.1784 \mathrm{j}$ & $u_{13}^{-}=0.4259+0.5741 \mathrm{i}$ \\
\hline 14 & Hunan & $u_{14}^{+}=0.3568+0.4648 \mathrm{i}+0.1784 \mathrm{j}$ & $u_{14}^{-}=0.4273+0.5727 \mathrm{i}$ \\
\hline 15 & Henan & $u_{15}^{+}=0.6496+0.3504 \mathrm{i}$ & $u_{15}^{-}=0.196+0.6256 \mathrm{i}+0.1784 \mathrm{j}$ \\
\hline 16 & Jiangxi & $u_{16}^{+}=0.3512+0.5868 \mathrm{i}+0.062 \mathrm{j}$ & $u_{16}^{-}=0.4749+0.5251 \mathrm{i}$ \\
\hline 17 & Liaoning & $u_{17}^{+}=0.4007+0.4208 \mathrm{i}+0.1784 \mathrm{j}$ & $u_{17}^{-}=0.4206+0.5794 \mathrm{i}$ \\
\hline 18 & Shaanxi & $u_{18}^{+}=0.4407+0.5593 \mathrm{i}$ & $u_{18}^{-}=0.3772+0.6228 \mathrm{i}$ \\
\hline 19 & Gansu & $u_{19}^{+}=0.2427+0.5789 \mathrm{i}+0.1784 \mathrm{j}$ & $u_{19}^{-}=0.5208+0.4792 \mathrm{i}$ \\
\hline 20 & Ningxia & $u_{20}^{+}=0.173+0.6485 \mathrm{i}+0.1784 \mathrm{j}$ & $u_{20}^{-}=0.6591+0.3409 \mathrm{i}$ \\
\hline 21 & Xinjiang & $u_{21}^{+}=0.3462+0.3978 \mathrm{i}+0.2561 \mathrm{j}$ & $u_{21}^{-}=0.4616+0.4805 \mathrm{i}+0.0579 \mathrm{j}$ \\
\hline 22 & Heilongjiang & $u_{22}^{+}=0.3627+0.4588 \mathrm{i}+0.1784 \mathrm{j}$ & $u_{22}^{-}=0.4134+0.5866 \mathrm{i}$ \\
\hline 23 & Inner Mongolia & $u_{23}^{+}=0.4104+0.4112 \mathrm{i}+0.1784 \mathrm{j}$ & $u_{23}^{-}=0.4272+0.5728 \mathrm{i}$ \\
\hline 24 & Qinghai & $u_{24}^{+}=0.1155+0.4072 \mathrm{i}+0.4772 \mathrm{j}$ & $u_{24}^{-}=0.8416+0.1584 \mathrm{i}$ \\
\hline 25 & Jilin & $u_{25}^{+}=0.2487+0.5271 \mathrm{i}+0.2242 \mathrm{j}$ & $u_{25}^{-}=0.53+0.47 \mathrm{i}$ \\
\hline
\end{tabular}

In addition to the above, it can also be seen from Figure 1 that the subjective weights and objective weights of some indicators are quite different. For example, the subjective weights of indicators I1, I2, I6, I9, and I16 are much larger than their objective weights. The objective weights of indicators I8, I10, I11, I12, I13, and I14 are much greater than the subjective weights. The indicators with subjective weight greater than objective weight mainly belong to macroeconomic and environmental protection. Due to the fact that these indicators are conducive to advancing electrical energy substitution, experts believe that the importance of these indicators is relatively large, but the differences between the regions in these aspects are not significant. Therefore, the subjective weights of these indicators are greater than the objective weights. The indicators with objective weights much larger than the subjective weights are mainly energy prices. The objective weights are larger due to the large difference in energy prices in each region. Due to the fact that experts believe that energy prices can be intervened by the government as needed and it has controllability, they think that the importance of these indicators is relatively low. Ultimately, the objective weights of these indicators are far greater than the subjective weights.

According to the potential value of electrical energy substitution, twenty-five provinces and cities can be divided into four categories, as shown in Figure 2. The areas with an electrical energy replacement potential above 0.6 are the first category, including Shandong, Henan, and Hebei. The areas with an electrical energy replacement potential between 0.5 and 0.6 are the second category, including Sichuan, Jiangsu, Shanxi, Shaanxi, Inner Mongolia, Liaoning, Zhejiang, and Heilongjiang. The areas with an electrical energy replacement potential between 0.4 and 0.5 are the third category, including Hunan, Hubei, Anhui, Xinjiang, Fujian, Jiangxi, Beijing, Shanghai, Chongqing, Tianjin, Jilin, and Gansu. The areas with an electrical energy replacement potential 0.4 or less are the fourth category, including the two provinces of Ningxia and Qinghai.

From Figure 2, we can see that although the potential value of electrical energy substitution in different regions is different, the potential value of electrical energy substitution in most regions is not much different, especially the areas in the second and third types. The difference between the area with the greatest potential for electrical energy substitution in the second category and the area with the lowest potential for electrical energy substitution in the third category is only 0.1734 . Combining the weights of the above indicator values, we can draw (1) electrical energy substitution as a national strategy, and local governments all have given policy support for the implementation of electrical energy substitution; (2) the use of energy throughout the country which is still dominated by fossil energy, and the proportion of nonfossil energy consumption is low. 


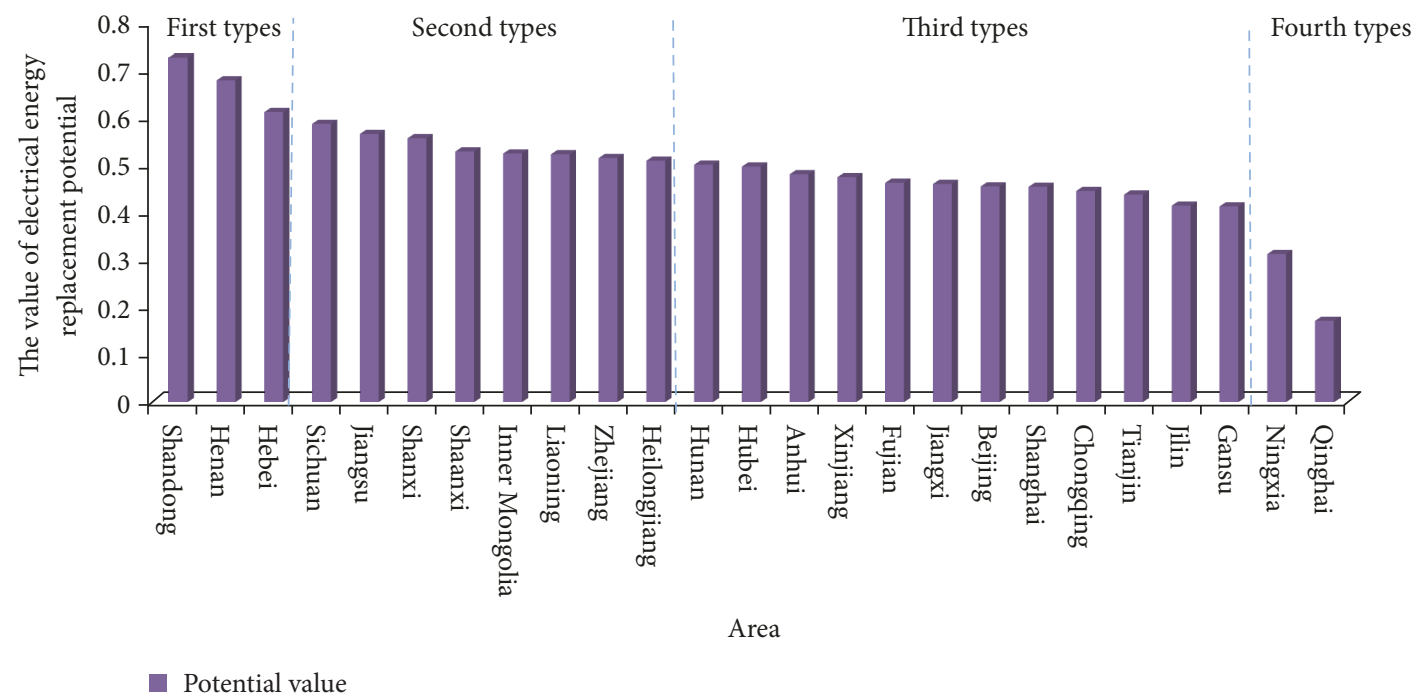

FIGURE 2: Regional electrical energy substitution potential values and classification.

TABLE 8: Relative close degree of each evaluated object and ideal point based on the distance of connection vectors.

\begin{tabular}{lcccc}
\hline Evaluation object & $d_{k}^{+}$ & $d_{k}^{-}$ & $c_{k}$ & Rank \\
\hline Beijing & 0.8185 & 0.6789 & 0.4534 & 18 \\
Shanghai & 0.8887 & 0.7346 & 0.4525 & 19 \\
Tianjin & 0.9511 & 0.7358 & 0.4362 & 21 \\
Chongqing & 0.9363 & 0.7473 & 0.4439 & 20 \\
Sichuan & 0.6543 & 0.9212 & 0.5847 & 4 \\
Hebei & 0.5638 & 0.8804 & 0.6096 & 3 \\
Shanxi & 0.6937 & 0.8633 & 0.5545 & 6 \\
Shandong & 0.3324 & 0.8702 & 0.7236 & 1 \\
Jiangsu & 0.6177 & 0.7978 & 0.5636 & 5 \\
Zhejiang & 0.7659 & 0.8069 & 0.5130 & 10 \\
Anhui & 0.8587 & 0.7895 & 0.4790 & 14 \\
Fujian & 0.8837 & 0.7561 & 0.4611 & 16 \\
Hubei & 0.8276 & 0.8119 & 0.4952 & 13 \\
Hunan & 0.8134 & 0.8099 & 0.4989 & 12 \\
Henan & 0.4955 & 1.0342 & 0.6761 & 2 \\
Jiangxi & 0.8769 & 0.7427 & 0.4585 & 17 \\
Liaoning & 0.7537 & 0.8194 & 0.5209 & 9 \\
Shaanxi & 0.7910 & 0.8808 & 0.5269 & 7 \\
Gansu & 0.9698 & 0.6777 & 0.4113 & 23 \\
Ningxia & 1.0660 & 0.4821 & 0.3114 & 24 \\
Xinjiang & 0.8070 & 0.7239 & 0.4729 & 15 \\
Heilongjiang & 0.8053 & 0.8296 & 0.5074 & 11 \\
Inner Mongolia & 0.7406 & 0.8101 & 0.5224 & 8 \\
Qinghai & 1.0844 & 0.2240 & 0.1712 & 25 \\
Jilin & 0.9447 & 0.6647 & 0.4130 & 22 \\
\hline
\end{tabular}

To facilitate the analysis of the characteristics of the electrical energy substitution potential in different types of areas, the data of Table 3 is processed as follows: (1) Normalizing the data in Table 3. (2) Using the normalized data to average each index values of each category, the formula is as (14), drawing the results in Figure 3.

$$
I_{\mathrm{i} m}=\frac{1}{t_{i}} \times \sum_{t=1}^{t_{i}} I_{i m t}
$$

where $i$ is the types, $m$ is the number of indicators, $\mathrm{m}=1,2, \ldots, 16$, and $t_{i}$ is the number of regions in the $i t h$ types, $t_{i}=1,2, \ldots, 25$.

As can be seen in Figure 3, the indicators that have large differences in the mean values of the four types are I1, I2, I3, I4, I5, I6, I7, and I9. These indicators are the main reasons for the differences in the potential for electrical energy substitution in different regions. For positive indicators, the mean values of the four categories of indicators decrease in turn. For negative indicators, the mean values of the four categories of indicators increase in turn. This shows that the potential for electric energy substitution in a region is the result of a combination of various factors. It also shows that the implementation of electric energy substitution is the result of the irreconcilability of various contradictions in the process of social development in China.

It can be seen from the above analysis that the first type of regional feature is that electrical energy substitution has obvious advantages and less resistance. Compared with other types, the first types have the advantages of developed economy and large population, and the consumption of fossil fuels such as coal, crude oil, and annual scatted coal is relatively large. It also faces serious air quality problems. At the same time, the consumption of natural gas is the lowest in four categories. Whether its industrial gas or residential gas, the price is slightly higher than that of other types. The electricity price in the first category is almost the same as in the second category and the third category, but it is obviously lower than the electricity price in the fourth category. The first category of regions is less competitive with natural gas and has certain advantages in terms of electricity price compared to other types of regions. Therefore, there 


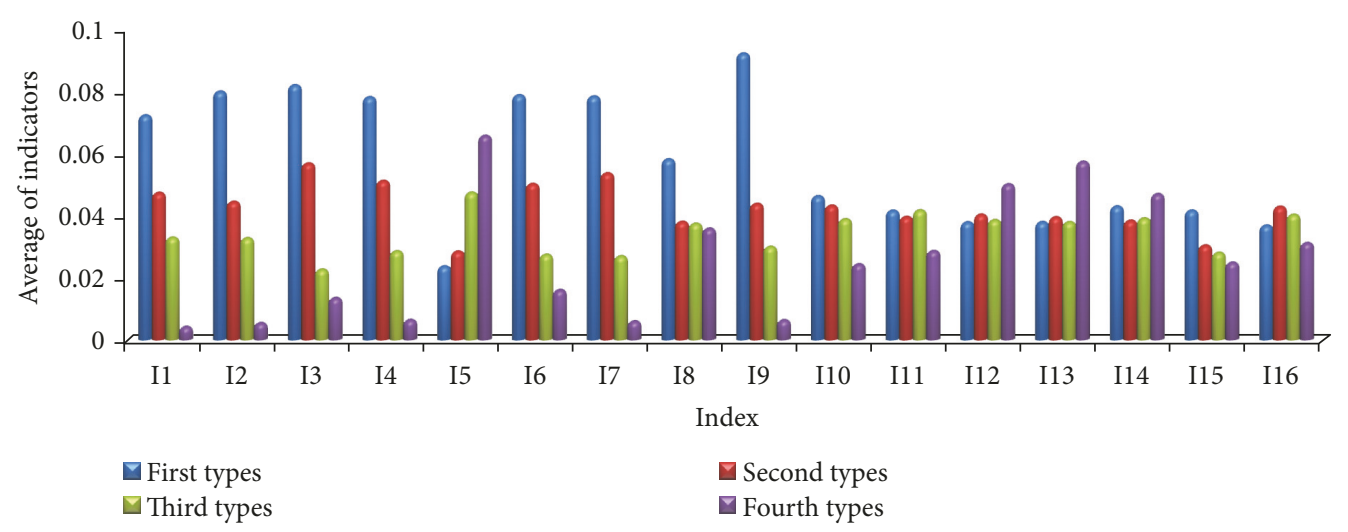

FIgURE 3: The average value of various categories of electrical energy substitution potential assessment indicators.

is a large market for electrical energy substitution and the first type of areas should become the preemptive areas for carrying out electrical energy substitution work. It should seize the opportunity and actively seize the electrical energy replacement market.

The second type of regional feature is the advantages of electrical energy substitution which begin to weaken, and the resistances begin to increase. The overall form of the second category is almost the same as that of the first category. However, its potential for electrical energy substitution is less than the potential for electrical energy substitution in the first category, mainly because the economic development level of the second category is lower than that of the first category, and the consumption of fossil energy is less than that of the first category too. In addition, the environmental pressures facing are not as big as the first category and there are no support policies as strong as the first category, but in spite of this, its environmental pressure and support policies are still greater than the third and fourth categories. However, compared with the first category, the second category contains more areas and the total amount of electrical energy substitution is greater than the first category. In addition, the second type of electrical energy surplus is larger than that of other categories, which indicates that the second category of regions has higher enthusiasm for electrical energy substitution. Therefore, the second category areas should be the main areas for carrying out electrical energy substitution work. It should be adapted measures according to local conditions and taking a kind of electrical energy substitution advantage field as a breakthrough, forming a breakthrough of electrical energy substitution from point to area.

The characteristic of the third category is that the advantages of electrical energy substitution are further weakened and resistances are further enhanced. The third category of electrical energy substitution potential is less than the first and second categories. Both the macroeconomic and fossil energy consumption are all less than the first and second categories, and its environmental protection constraints and support policies are also slightly lower than the first and second categories. Although the surplus of electric energy is larger than that of the first category, the willingness to electrical energy replacement is stronger; there is a greater competition with natural gas. The consumption of natural gas in the third type is greater than that of the first and second types. The price of industrial gas in the third type is also slightly lower than the price of industrial gas in the second type, but the price of electricity in the third type is almost the same as the price of the second type, so it has no economic advantages. The third category is the one that contains the maximum number of regions. Although the advantages of electrical energy substitution are weak and the resistances are relatively large, it is a relatively larger market. Therefore, we must make gradual progress and achieve gradually substitution.

The fourth category is characterized by the disappearance of the advantages of electrical energy substitution and stronger resistances. The fourth category of regions has the smallest potential for electrical energy substitution. Compared with the other three types, fossil energy consumption is minimal, but the consumption of natural gas is larger than that of other three types, and the price of gas is extremely low. On the contrary, the electricity price in fourth types is higher than that of other types. Electrical energy substitution has almost no advantages in this type. Therefore, in regions where the level of gasification is relatively strong, electric energy substitution can be carried out in the form of "gas-electricity complementarity".

\section{Conclusion}

As a part of the energy development strategy, electrical energy substitution plays an important role in promoting the energy consumption revolution, implementing the national energy strategy, and promoting the sustainable development of energy cleanliness. This paper constructed a regional electrical energy substitution potential evaluation index system that includes five first-level indicators and sixteen secondlevel indicators based on comprehensive consideration of the influencing factors and regional differences in the potential of electrical energy substitution. Using the combination of cloud model and entropy method to determine the weight of each indicator, the improved TOPSIS method by the connection degree was used to comprehensively evaluate the electrical energy substitution potential in the twenty-five provinces and 
cities within the jurisdiction of the State Grid. The validities of the indicator system and evaluation method were verified. The evaluation results indicating that four evaluation indexes that have the greatest impact on the potential for electrical energy substitution are support policies, coal consumption, annual scatted coal consumption, and crude oil consumption, respectively. The three regions with the greatest potential for electrical energy replacement are Shandong, Henan, and Hebei. Finally, twenty-five regions are divided into four categories according to the potential value of electrical energy substitution potential. The characteristics of each category region were analyzed and accordingly the corresponding electrical energy substitution promotion strategies were put forward.

In short, steadily advancing the replacement of electrical energy will help build a new level of higher-level electrical energy consumption market, expand electrical energy consumption, upgrade China's electrification level, and improve people's quality of life. At the same time, it will also beneficial to drive the development of related equipment manufacturing industries and expand new economic growth points. Constructing a comprehensive evaluation index system and evaluation method for the potential of regional electrical energy replacement is helpful to understand the potential of electrical energy substitution in each region and provides strong support for subsequent national grid companies to formulate electrical energy substitution strategic measures and implementation according to local conditions. At the same time, it provides certain reference and decision-making support for government departments, power generation and power sales companies, and other stakeholders.

\section{Data Availability}

The data used to support the findings of this study are available from the corresponding author upon request.

\section{Conflicts of Interest}

The authors declare that they have no conflicts of interest.

\section{Acknowledgments}

This work was supported by the National Social Science Fund of China (Grant no. 15BGL145), Hebei Provincial Social Science Fund (Grant no. HB15YJ038), and Hebei Province Soft Science Fund (Grant no. 16454302D).

\section{References}

[1] K. Dennis, "Environmentally beneficial electrification: Electricity as the end-use option," The Electricity Journal, vol. 28, no. 9, pp. 100-112, 2015.

[2] K. Dennis, K. Colburn, and J. Lazar, "Environmentally beneficial electrification: The dawn of 'emissions efficiency"' The Electricity Journal, vol. 29, no. 6, pp. 52-58, 2016.

[3] Z. A. Needell, J. McNerney, M. T. Chang, and J. E. Trancik, "Potential for widespread electrification of personal vehicle travel in the United States," Nature Energy, vol. 1, no. 9, p. 16112, 2016.

[4] G. P. Moreda, M. A. Muñoz-García, and P. Barreiro, "High voltage electrification of tractor and agricultural machinery - A review," Energy Conversion and Management, vol. 115, pp. 117131, 2016.

[5] S. S. Raghavan and A. Khaligh, "Electrification potential factor: Energy-based value proposition analysis of plug-in hybrid electric vehicles," IEEE Transactions on Vehicular Technology, vol. 61, no. 3, pp. 1052-1059, 2012.

[6] W. Ke, S. Zhang, Y. Wu et al., "Assessing the future vehicle fleet electrification: The impacts on regional and urban air quality," Environmental Science \& Technology, vol. 51, no. 2, p. 1007, 2017.

[7] W. Dong-sheng, L. Ming-rui, B. Xiang-fei, and D. Hua, “The situation analysis of civil coal in the Beijing-Tianjin-Hebei region," Coal Technology, vol. 3, no. 2016, pp. 47-49, 2016.

[8] F. S. Javadi, B. Rismanchi, M. Sarraf et al., "Global policy of rural electrification," Renewable \& Sustainable Energy Reviews, vol. 19, no. 1, pp. 402-416, 2013.

[9] D. Steinberg et al., "Electrification \& decarbonization: Exploring U.S. energy use and greenhouse gas emissions in scenarios with widespread electrification and power sector decarbonization," National Renewable Energy Laboratory, vol. 1, no. 2017, p. 111, 2017.

[10] Z. Xu, M. Nthontho, and S. Chowdhury, "Rural electrification implementation strategies through microgrid approach in South African context," International Journal of Electrical Power \& Energy Systems, vol. 82, pp. 452-465, 2016.

[11] L. Molyneaux, L. Wagner, and J. Foster, "Rural electrification in India: Galilee Basin coal versus decentralised renewable energy micro grids," Journal of Renewable Energy, vol. 89, pp. 422-436, 2016.

[12] P. A. Trotter, "Rural electrification, electrification inequality and democratic institutions in sub-Saharan Africa," Energy for Sustainable Development, vol. 34, pp. 111-129, 2016.

[13] R. Pode, G. Pode, B. Diouf et al., "Solution to sustainable rural electrification in Myanmar," Renewable \& Sustainable Energy Reviews, vol. 59, pp. 107-118, 2016.

[14] J. Zhang and J. Z. Zhang, "Marketing strategies and implementation of electric power alternatives," Power Demand Side Management, 2015.

[15] X. Zhang, W. Yang, Z. Li, C. Liu, and J. Zhou, "Research on comprehensive benefit evaluation model of electrical energy alternative with development mode of new-type urbanization," in Proceedings of the 4th International Conference on Information Technology and Management Innovation, Shenzhen, China, September 2015.

[16] D. L. Cao, Y. Yuan, and L. I. Zhi xiang, "Application and efficiency evaluation of alternative energy," Power System \& Clean Energy, 2011.

[17] ZengHuan, Research on Technical Economic Analysis and Policyof Electric Energy Replacement on Rural Areas of Beijing Tianjin -Hebei, North China Electric Power University, 2017.

[18] Z. H. Yang, "Planar model and its application in prediction," Chinese Journal of Computers, vol. 21, no. 11, pp. 961-969, 1998.

[19] S. Yuan, L. I. De, Y. Xiao et al., "Reliability evaluation of electronic products based on cloud models," Acta Electronica Sinica, 2000.

[20] X. Li and D. Li, "A new method based on cloud model for discretization of continuous attributes in rough sets," Pattern Recognition \& Artificial Intelligence, vol. 16, no. 1, pp. 33-38, 2003. 
[21] Y. Zhang, L. I. Chang-Zheng, J. Wang et al., "The Method of System Index Test-Set Production Based on Cloud Model," Acta Simulata Systematica Sinica, 2003.

[22] H.-B. Duan, D.-B. Wang, X.-F. Yu et al., "Improvement of ant colony algorithm based on cloud models theory," Journal of Harbin Institute of Technology, 2005.

[23] C.-S. Yan and Y.-J. Li, "Analysis of dynamic consumer detailed segmentation model based on cloud model," Journal of Harbin Institute of Technology, vol. 39, no. 2, pp. 299-302, 2007.

[24] G.-Y. Zhang, Y. Sha, X.-H. Liu et al., "High dimensional cloud model and its application in multiple attribute evaluation," Journal of Beijing Institute of Technology, vol. 24, no. 12, pp. 10651069, 2004.

[25] Y. E. Qiong, L. I. Shao-Wen, Y. H. Zhang et al., "Cloud model and application overview," Computer Engineering \& Design, vol. 32, no. 12, pp. 4198-4201, 2011.

[26] X. Y. Du, Q. J. Yin, K. D. Huang et al., “Transformation between qualitative variables and quantity based on cloud models and its application," Systems Engineering \& Electronics, vol. 30, no. 4, pp. 772-776, 2008.

[27] R. Jian, "Linguistic-stochastic multi-criterion decision-making method based on cloud model," Computer Integrated Manufacturing Systems, vol. 18, no. 12, pp. 2792-2797, 2012.

[28] Y. Zhang, D. Zhao, D. Li et al., "The similar cloud and the measurement method," Information \& Control, vol. 33, no. 2, pp. 129-132, 2004.

[29] X. Shidong and GengXiuli, "Method of multi-attribute group decision-making by combining cloud model and TOPSIS," Application Research of Computers, vol. 34, no. 10, pp. 29642967, 2017.

[30] Z.X. Yang, "Research on the comprehensive evaluation of development of economic zone ability based on set pair analysisaround the bohai sea," Mathematics in Practice \& Theory, 2009.

[31] M. Zhang and Z. F. Zhou, An Improved TOPSIS Method Based on Connection Degree, Systems Engineering, 2008.

[32] G. Han, W. Chen, Z. Feng et al., Selection of Enterprise's Cooperative Innovation Partners-Based on PSO Fixed Weight and Ameliorated TOPSIS Method, Science Research Management, 2014. 


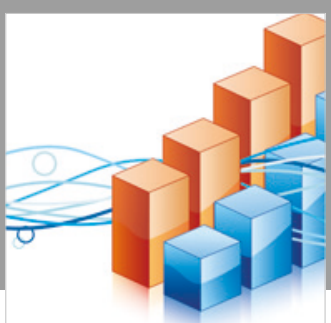

Advances in

Operations Research

\section{-n-m}
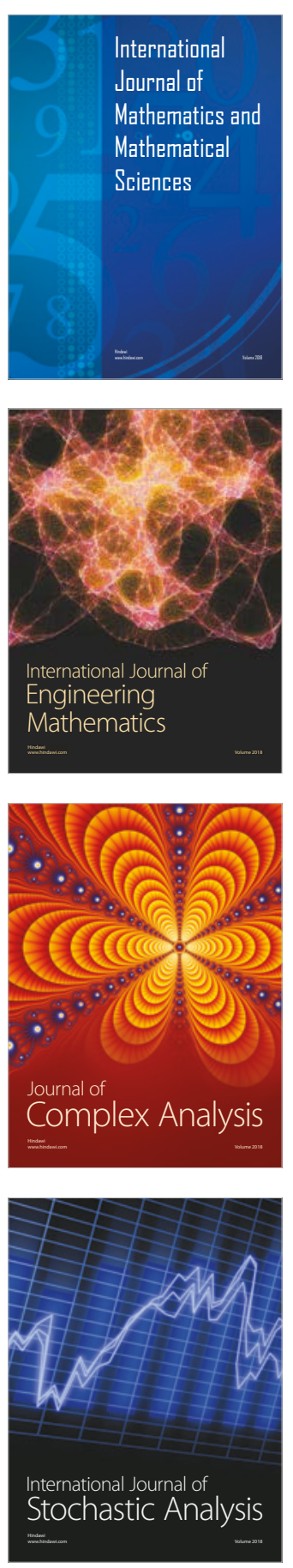
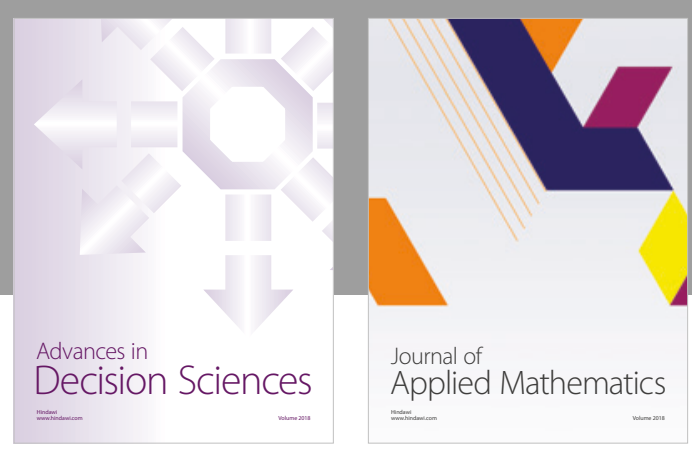

Journal of

Applied Mathematics
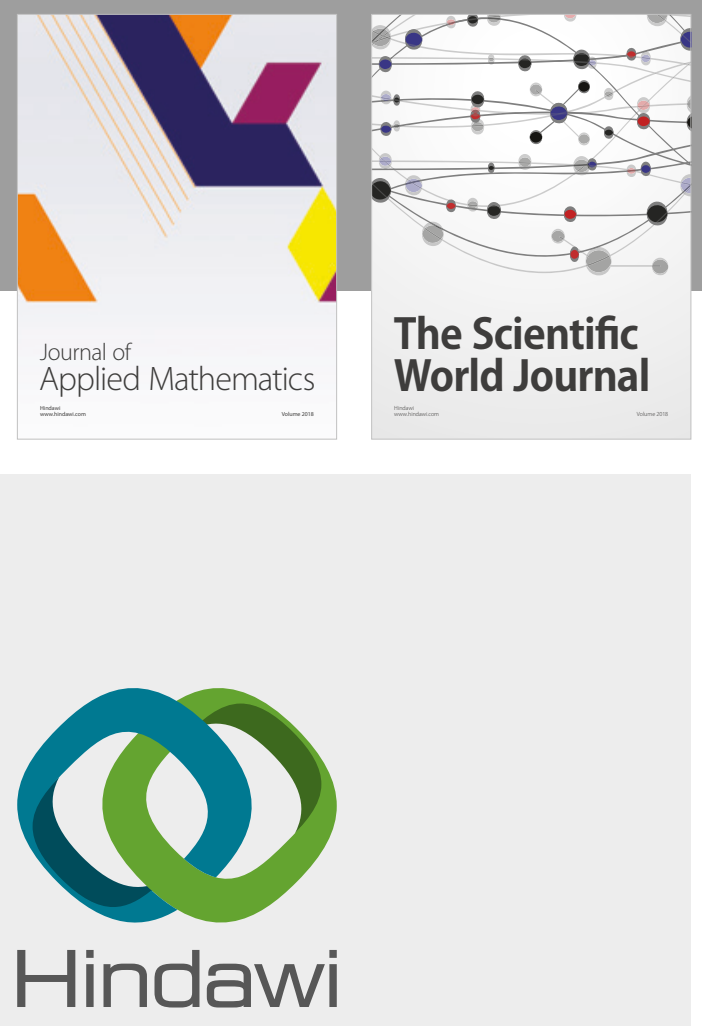

Submit your manuscripts at

www.hindawi.com

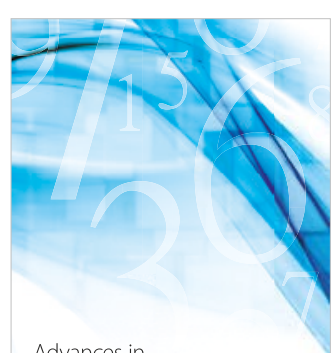

Advances in
Numerical Analysis
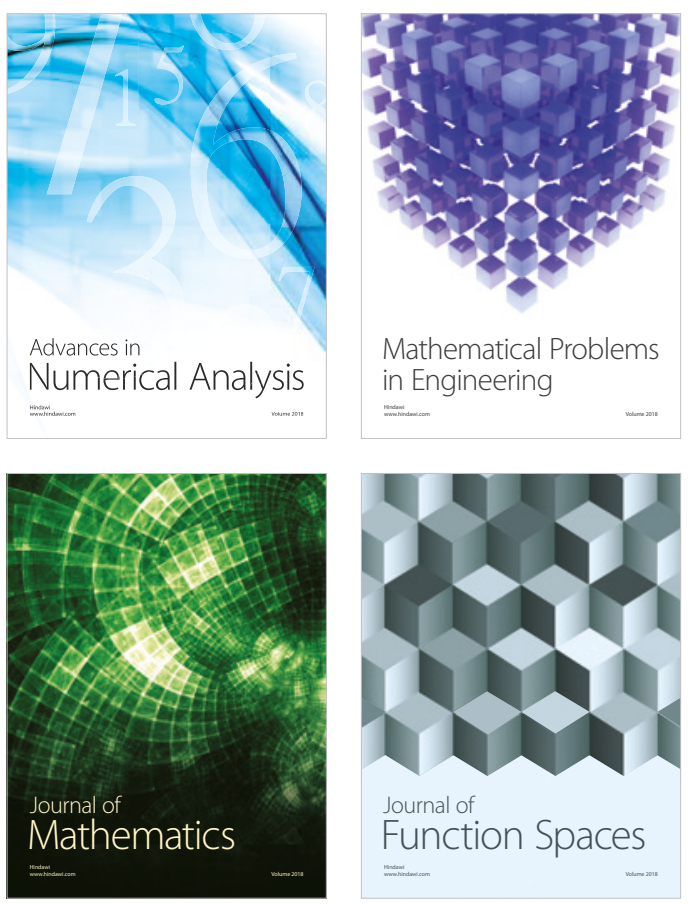

Mathematical Problems in Engineering

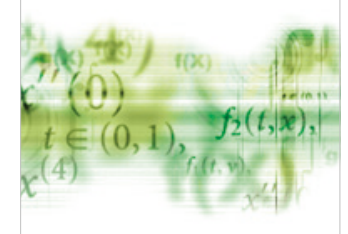

International Journal of

Differential Equations

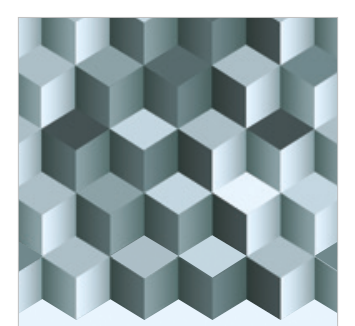

Journal of

Function Spaces

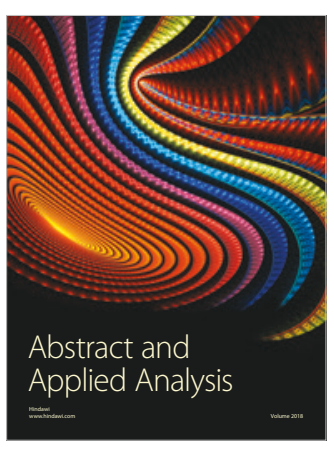

The Scientific

World Journal

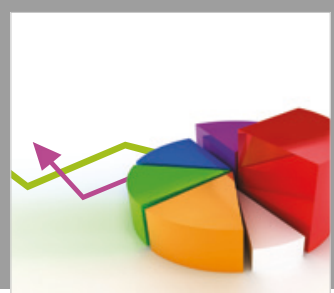

Journal of

Probability and Statistics
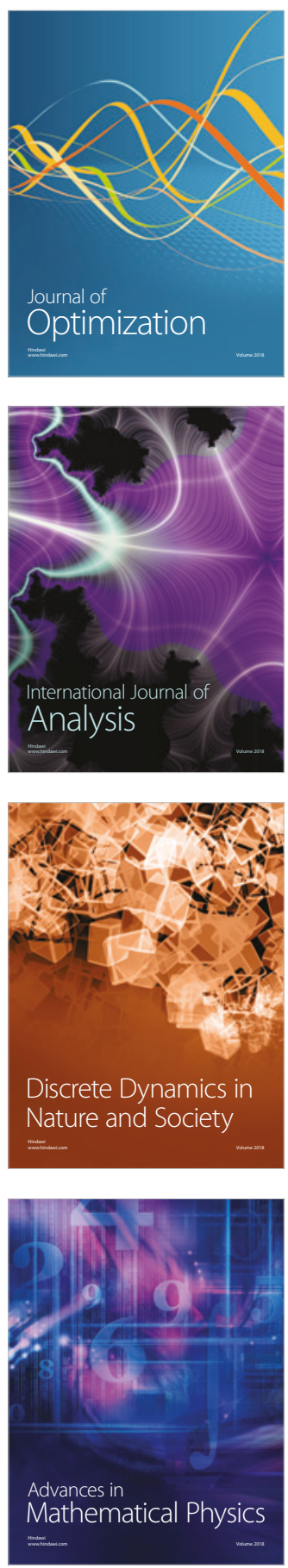